\title{
'Containers' for self-healing epoxy composites and coating: Trends and advances
}

\author{
P. Vijayan ${ }^{1 *}$, M. A. AlMaadeed ${ }^{1,2}$ \\ ${ }^{1}$ Center for Advanced Materials, Qatar University, P.O. Box 2713, Doha, Qatar \\ ${ }^{2}$ Materials Science and Technology Program, Qatar University, P.O. Box 2713, Doha, Qatar
}

Received 6 November 2015; accepted in revised form 14 January 2016

\begin{abstract}
The introduction of self-healing functionality into epoxy matrix is an important and challenging topic. Various micro/nano containers loaded self-healing agents are developed and incorporated into epoxy matrix to impart self-healing ability. The current report reviews the major findings in the area of self-healing epoxy composites and coatings with special emphasis on these containers. The preparation and use of polymer micro/nano capsules, polymer fibers, hollow glass fibers/bubbles, inorganic nanotubes, inorganic meso- and nano-porous materials, carbon nanotubes etc. as self-healing containers are outlined. The nature of the container and its response to the external stimulations greatly influence the self-healing performance. The self-healing mechanism associated with each type of container and the role of container parameters on self-healing performance of self-healing epoxy systems are reviewed. Comparison of the efficiency offered by different types of containers is introduced. Finally, the selection of containers to develop cost effective and green self-healing systems are mentioned.
\end{abstract}

Keywords: smart polymers, epoxy, self-healing, coating

\section{Introduction}

Excellent adhesion, high mechanical strength, high thermal stability and high chemical and corrosion resistance of epoxy make this material suitable for versatile applications like structural adhesives, protective coatings and resin matrices for composites [1]. However, as an inherently brittle material, epoxy thermosets are highly susceptible to defects/cracks [1-3]. Fracture/fatigue loadings, thermal effects or any kind of environmental effects influence the matrix service life. In general, the material failure starts at nano-scale, which then enlarges to micro- and then to macro-scale until failure occurs. It is difficult to detect and repair these micro/nano cracks formed in the structural components [4]. Hence, it is promising to develop self-healing epoxy composites that can repair damages by themselves without any external intervention to recover their functions.
In a similar way, the introduction of self-healing functionality into protective coating is a better alternative for a long-term corrosion protection of metallic structures by eliminating toxic chromate based coatings. The self-healing coating provides an active protection to the metallic surface not only by mechanical covering but also by protection even after partial damage of the coating [5-7]. In self-heling coatings controlled release of the corrosion inhibitor has been triggered by the changes in local environment (change in $\mathrm{pH}$ ).

The development of self-healing technology for epoxy materials attracted growing interest and various methods have been reported based on healing agents, healing agent containers, healing mechanisms etc. A great deal of attention has been paid to design self-healing epoxy after their first introduction in 2001 by White et al. [8]. In this breakthrough

\footnotetext{
${ }^{*}$ Corresponding author, e-mail: poornimavijayan@qu.edu.qa (C) BME-PT
} 
self-healing concept, healing agent (dicyclopentadiene) encapsulated inside a poly (urea-formaldehyde) microcapsule reacted with a catalytic chemical trigger (Grubbs' catalyst) within epoxy matrix to provide self-healing ability. The successive reports on selfhealing epoxies, disclosed various combination of self-healing components and healing mechanisms. Among them, the containers to encapsulate the healing agent have been investigated widely. These containers are specially designed to release the loaded healing agents in case of the failure of the epoxy structure due to any kind of external stimulus. The nature of the container such as the material, morphology, shell wall thickness, storage stability, core content etc. and its response to the external stimulations are of great importance in determining the self-healing performance. The external stimulation to trigger the release of healing agent from the containers includes light, mechanical impact, local change in $\mathrm{pH}$ during the corrosion process etc.

Self-healing polymers are subject to intense discussion in the scientific community during the last decade [9-11]. The studies on micro/nanocapsules used for self-healing coatings were reviewed by Samadzadeh et al. [12]. Wu et al. [13] reviewed the trends and developments in self-healing polymeric materials including preparation and characterization of the self-healing systems, evaluation of selfhealing efficiencies in thermoplastic and thermoset materials. Yang et al. [14] reviewed different aspects of self-healing polymers including the thermodynamic requirements and chemical reactions for selfhealing, encapsulation process, remote self-healing etc. A specific area in self-healing polymers i.e. container based self-healing polymer coatings wase reviewed by Shchukin [15]. Fayyad et al. [16] discussed in detail different techniques used to follow the self-healing process in protective epoxy coatings.
However, the absence of a systematic review in the area self-healing epoxy in specific, make the current review unique, which focuses on self-healing agent loaded containers used in epoxy matrix.

The present review aims to report the investigations on the development and use of various micro/nano containers for epoxy composites and coatings. An ideal self-healing container should be resistant to solvents, temperature and mechanical stresses such as mixing, curing etc. during the manufacturing processes by maintaining the healing agents inside. At the same time, the container should break upon propagation of cracks through the matrix and release enough healing agents to recover the crack. Extensive research works were reported to achieve containers which fulfill these criteria. Researchers used different types of self-healing agent loaded containers with hollow cavity of different shapes including polymer capsules, polymer fibers, hollow glass fibers and capsules, inorganic capsules and tubes etc. in the size range from micro to nano. Figure 1 shows containers of different origin which are capable of loading healing agents inside their cavity. The influence of container parameters on the self-healing performance is reviewed in detail. The potential of inorganic nanotubes, mesoporous materials and carbon nanotubes materials to act as multifunctional containers for epoxy is proposed.

\section{Polymer capsules as self-healing agent containers}

\subsection{Preparation of polymer microcapsules}

In situ emulsion polymerization, interfacial polymerization, vacuum infiltration etc. are used to prepare the polymer microcapsules. Among them in situ emulsion polymerization is the most widely used method for the preparation of polymer microcapsules. Different types of liquid healing agents such as

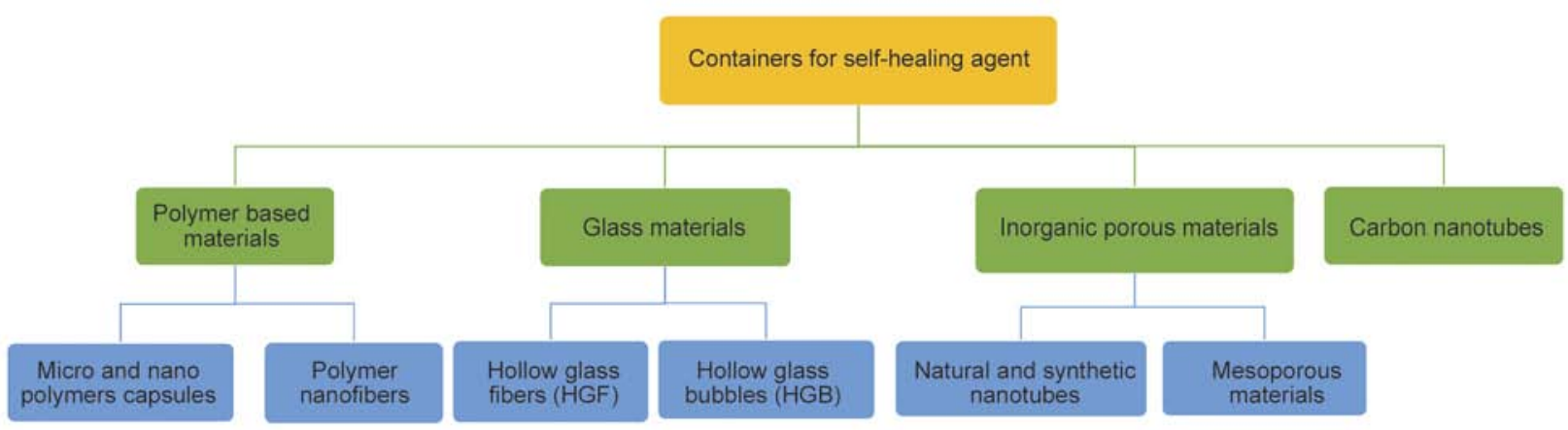

Figure 1. Containers of different origin capable of loading healing agents inside 
dicyclopentadiene (DCPD), organic solvents, epoxy resin, curing agents and drying oils are encapsulated inside polymeric shells like poly (urea-formaldehyde) (PUF), poly (melamine-formaldehyde) (PMF) etc. using in situ polymerization reaction [17]. White and coworkers $[8,18]$ prepared DCPD encapsulated PUF microcapsules in oil-in-water emulsion. The processing parameters like agitation speed, temperature, emulsifier concentration etc. can influence the morphology, shell wall parameters, size distribution, storage stability and core content of these microcapsules.

The procedure adopted by White and coworkers $[8$, 18] was also extended to encapsulate other healing materials in PUF shell. Organic solvents encapsulated polymer capsules were prepared by researchers. Chlorobenzene was encapsulated in PUF shell using in situ polymerization method with an average diameter of $160 \pm 20 \mu \mathrm{m}$ [19]. In an advanced attempt, co-encapsulation of epoxy monomer with solvents in PUF shells were done by dissolving epoxy resins in solvents before adding to the emulsion mixture $[19,20]$. Drying oil encapsulated microcapsules, specifically designed for self-healing epoxy coatings, were also generated by in situ polymerization [21].

The self-healing based on DCPD or solvent encapsulated microcapsules make use of chemistries which are different from that of the matrix. This might result in deterioration of the mechanical properties of the healed area. So researchers found methods for the safe encapsulation of both epoxy resin and curing agent. While using epoxy as reactive healing agent, the microencapsulation of epoxy monomer was done by a two-step process [22]. Initially, urea and formaldehyde were pre-polymerized and then formed microcapsules via in situ condensation. In another attempt, epoxy was encapsulated in an epoxy shell itself [23]. Liu et al. [23] prepared microcapsules with epoxy as the core healing agent and epoxy-amine polymer as the shell by interfacial polymerization of epoxy resin droplets with ethylenediamine (EDA). The reaction of epoxy which cannot be dissolved in water with EDA which is readily dissolved in water at the interface of epoxy droplets to form the shell material.

Though it is easy to achieve the epoxy encapsulation, encapsulation of liquid amine hardeners is difficult due to their amphoteric nature and high reactivity. The conventional amine hardener could not encapsulate by urea-formaldehyde shell under acidic conditions. Researchers chose mercaptan as curing agent suitable for encapsulation purpose [24, 25]. Since mercaptan is very active, it was microencapsulated with melamine-formaldehyde by an improved in situ polymerization approach. The mercaptanloaded PMF capsules showed high storage stability. The catalyst was infiltrated into the mercaptanloaded PMF capsules, to produce microcapsules containing both mercaptan and its amine catalyst.

Later, a new method to encapsulate amine hardeners was introduced [26]. In this method diethylenetriamine was infiltrated into hollow PUF microcapsules using vacuum process. Initially, hollow PUF microcapsules were prepared by a poly-condensation reaction of urea-formaldehyde pre-polymer on the surface of entrained air bubbles. These hollow capsules were immersed in diethylenetriamine and carried out the vacuum infiltration for several hours to encapsulate the amine inside the PUF capsules. In an another attempt, polyetheramine, a flowable and low temperature curable curing agent was successfully encapsulate in poly(methylmethacrylate) (PMMA) shell [27]. In this case, PMMA microcapsules were prepared by a controlled phase separation process within droplets of an oil-in-water $(\mathrm{O} / \mathrm{W})$ emulsion. Successively, the solvent evaporation technique was employed to form a PMMA shell around the polyetheramine core.

Very recently, a facile method of preparation of microcapsules based on Pickering emulsion, in which the solid particles adsorbed on oil-water interface instead of surfactants in traditional emulsion was introduced [28, 29]. Soild particles like nanoclay and lignin are remarkably stable to protect droplets from aggregation. Yi et al. [29] used cheap and ecofriendly material-lignin as Pickering emulsion stabilizer and the active hydroxyl groups in the chemical structure of lignin could react with isocyanate groups in oil phase and reinforced the stability of emulsions. Isophorone diisocyanate, (IPDI) was effectively loaded in lignin nanoparticle-stabilized oil-in-water $(\mathrm{O} / \mathrm{W})$ Pickering emulsion templates (Figure 2).

\subsection{Preparation of polymer nanocapsules}

To develop thin polymer coating, the incorporation of nanocapsules is better choice than microcapsules. The possible lower capsule diameter limit of the PUF microcapsule developed by the in situ polymerization was $10 \mu \mathrm{m}$ [8]. However, a combination of ultra- 

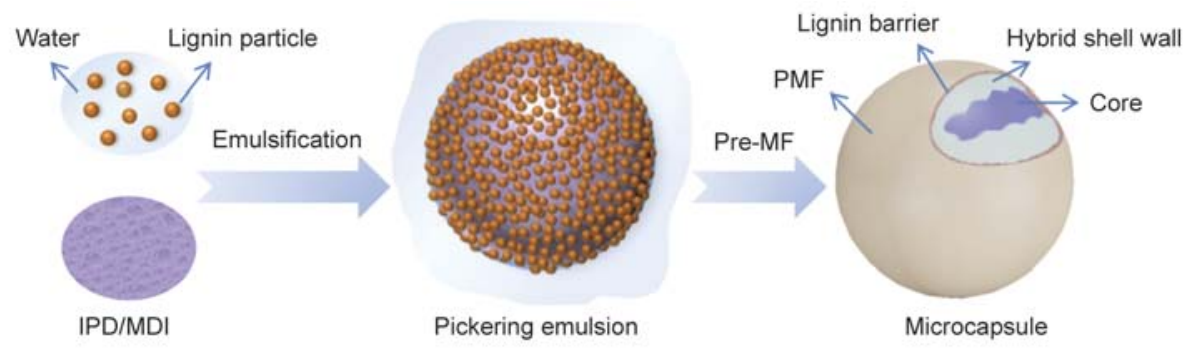

Figure 2. Schematic for the synthesis process of multilayer composite microcapsules loaded with healing agents based on Pickering emulsion templates [29]

sonication and in situ encapsulation techniques was used to produce submicron and nano PUF capsules filled with DCPD [30]. This method was reported to produce nano-capsules with smooth outer surface and thin shell walls.

Zhao et al. [31] introduced a general method to develop nanocapsules from polymers like poly (Llactide) (PLLA), poly(vinyl acetate) (PVAc), poly (methyl methacrylate) (PMMA), poly(vinyl formal) (PVF) and poly(vinyl cinnamate) (PVCi) using combination of solvent evaporation and miniemulsion techniques. The steps involved in this process is shown in Figure 3. Initially, a homogeneous hydrophobic phase containing pre-synthesized polymer and healing agent in a good polymer solvent was ultrasonicated with aqueous surfactant solution, to obtain miniemulsion droplets. Further upon good solvent evaporation, the nanocapsule encapsulated with healing agent was formed through internal phase separation. This method can be applied to encapsulate hydrophobic healing agents like solvents and monomers, reflecting their use in self-healing epoxy systems.

\subsection{Polymer capsules in epoxy composites}

Polymer capsules are developed as self-healing containers to fracture along the crack to release the healing agent into the failure site. The understanding of the micromechanical properties of these encap- sulated shells using nanoindentation technique can help in predicting the self-healing performance of microcapsule incorporated epoxy systems [32]. In addition to the ability to act as healing agent reservoirs, theses containers can also serve as a toughening agent for virgin epoxy. The detailed toughening mechanism operates in fluid filled PUF microcapsules embedded epoxy was investigated. The toughening mechanisms induced by these microcapsules are found to be different from that by solid particle fillers [33, 34]. The increased hackle marking and subsurface micro-cracking were identified in fluidfilled microcapsules incorporated epoxy. It was reported that the PUF microcapsules with optimal wall thickness $(56 \pm 5 \mu \mathrm{m})$, diameter $(400 \pm 50 \mu \mathrm{m})$ and surface morphology have the lower permeability and high stability. This makes them applicable to polymers fabricated at higher temperature $\left(<250^{\circ} \mathrm{C}\right)$ [35]. However, it was found that the presence of microcapsules caused a reduction in modulus and strength of the matrix $[33,24]$.

The self-healing epoxy system introduced by White et al. [8] used PUF microcapsules with thin shell to encapsulate DCPD as healing agent. When the crack propagates thorough the matrix, the embedded microcapsules ruptured to release the DCPD monomer into the crack. Grubbs catalyst embedded in the matrix initiated the polymerization of the released DCPD via ring-opening metathesis polymerization (ROMP)

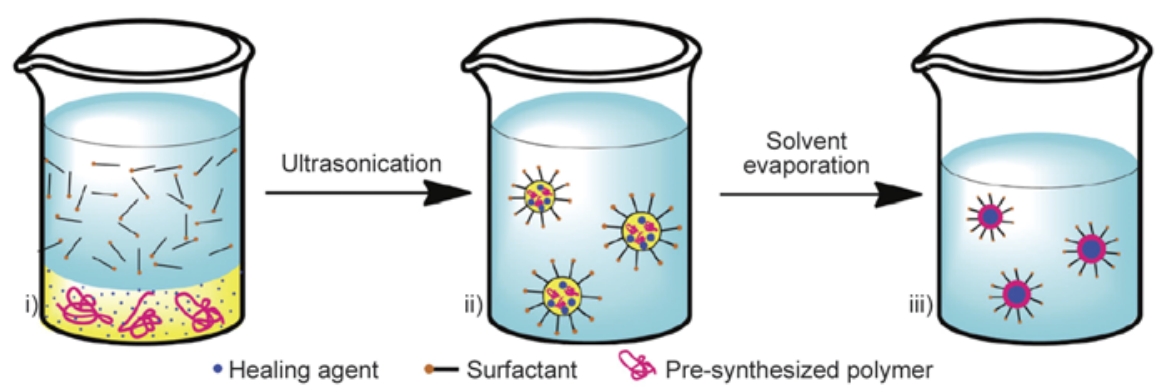

Figure 3. Schematic illustration of the general route towards fabrication of healing agent-filled nanocapsules from miniemulsions using pre-synthesized polymers [31] 
to rebond the crack plane at room temperature. Figure 4a schematically shows the self-healing mechanism operates in encapsulated DCPD/Grubbs catalyst based self-healing epoxy systems. The scanning electron microscopic (SEM) image of ruptured PUF microcapsule is shown in Figure 4b. In this case, the self-healing process was found to influence the concentration and size of PUF microcapsules [36]. It was found that a lower capsule concentration of $5 \mathrm{wt} \%$ achieved a satisfactory healing. However, in this case, the size of the microcapsule did not show a prominent effect on fracture toughness $\left(K_{\mathrm{IC}}\right)$ and healing efficiency $\left(\eta=K_{\mathrm{IC}}\right.$ healed $/ K_{\mathrm{IC}}$ virgin), even though the capsule size had a direct influence on the volume of DCPD monomer released. The fracture toughness per volume fraction of capsules was found to be higher for $1.5 \mu \mathrm{m}$ capsules than for larger capsules $(180 \mu \mathrm{m})$. The PUF nanocapsules synthesized by Suryanarayana et al. [21] were found to provide better compatibility with the matrix. The dispersion of DCPD filled PUF nanocapsules in epoxy matrix caused a significant increase in fracture toughness with a slight decrease of tensile strength.

The microcapsules made of urea-formaldehyde filled with DCPD was used in successive research to develop carbon fiber reinforced epoxy structural composites with self-healing ability [37]. The encapsulation of fluorescent dye along with DCPD into the melamine-urea-formaldehyde (MUF) shell was effectively used to observe the recovering process using fluorescence microscopy [38]. The transport of self-healing agent between crack planes released from a microcapsule were traced using fluorescence microscopy in cracked epoxy incorporated with MUF microcapsules containing DCPD with fluorescent dye.

The limitations of DCPD/Grubbs catalyst based self-healing system includes catalyst unavailability, cost, environmental toxicity, instability, and difficult materials processing could be eliminated by an economical and simple way of using encapsulated solvents to recover the virgin properties of epoxy system [19]. Chlorobenzene loaded PUF microcapsules were incorporated into the epoxy matrix. When a crack propagated through the material, the solvent was released upon cleavage of the capsules and healed the crack. The healing mechanism they proposed involved the local swelling of the matrix by the solvent which allowed the accessibility of residual amines and further crosslinking with residual epoxy functionality. The self-healing ability of the solvent-based system could be further improved by

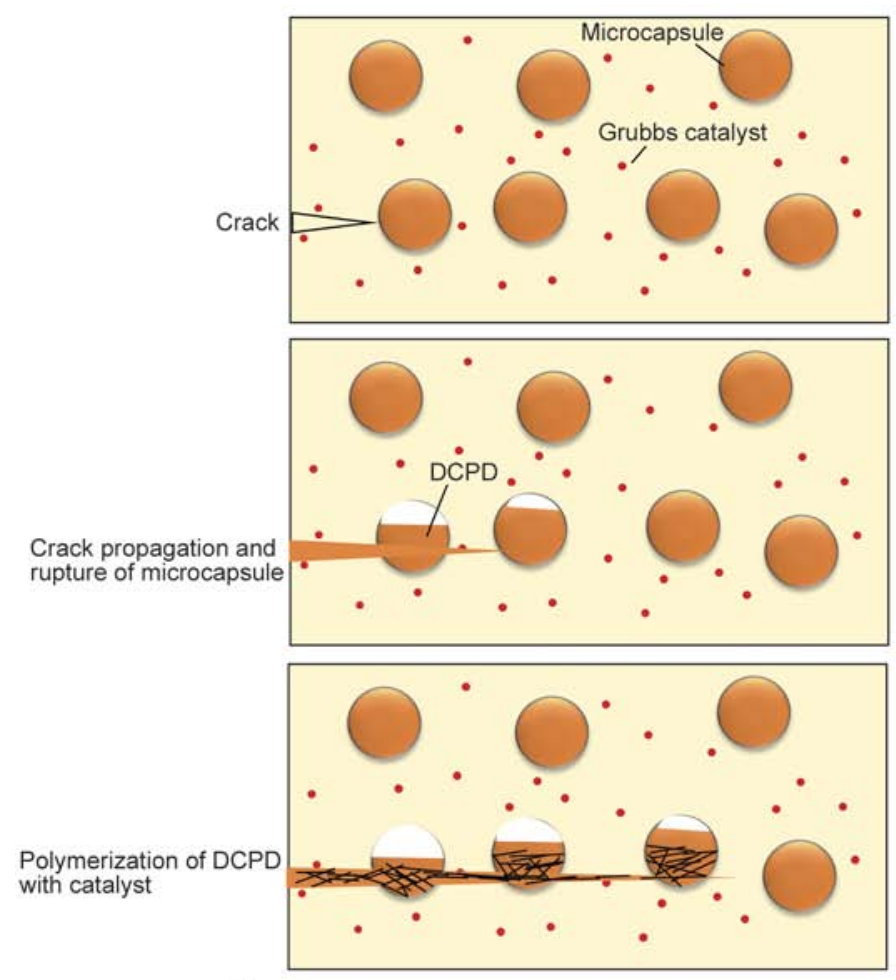

a)

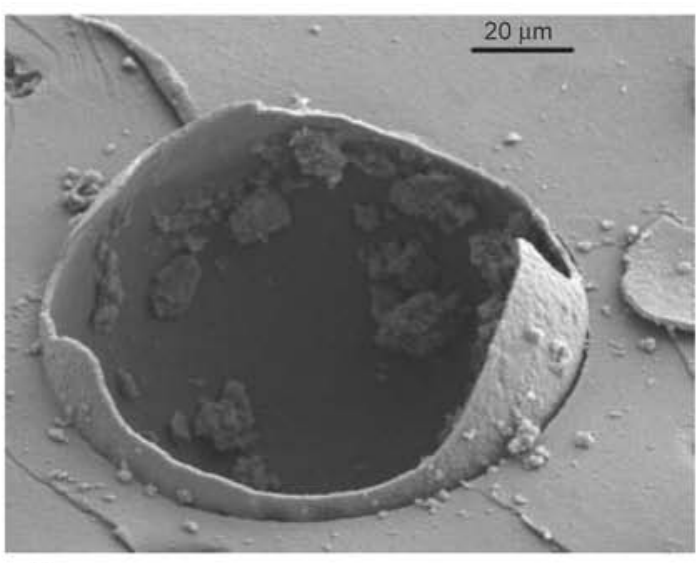

b)

Figure 4. a) The schematic representation of self-healing concept introduced by White et al. in encapsulated DCPD/Grubb's catalyst based epoxy self-healing systems, b) scanning electron microscope image shows the fracture plane of a selfhealing material with a ruptured PUF microcapsule in a thermosetting matrix [8] 
using an epoxy monomer co-encapsulated with solvents $[20,39]$. In such case, the additional epoxy monomer delivered to the crack plane provided additional crosslinking to have new thermoset material to the original matrix interface with multiple healing events. The solvent-based self-healing concept was extended to greener solvents like phenylacetate and ethyl phenylacetate [39, 40]. These aromatic ester are significantly less toxic solvents than chlorobenzene. Coope et al. [40] incorporated PUF microcapsule containing mixture of ethyl phenylacetate/epoxy mixture into scandium(III) triflate catalyst embedded epoxy. In this system, the epoxy monomer from the ruptured microcapsule undergoes ring-opening polymerization in contact with dispersed catalyst. Here the self-healing activity was promoted by the swelling of epoxy matrix by ethyl phenylacetate to facilitate catalyst dissolution.

The PUF encapsulated ethyl phenylacetate/epoxy mixture was used along with shape memory alloy wires in epoxy matrix to allow the healing of larger damage volumes [41, 42]. Here the use of shape memory alloy wires along with ethyl phenylacetate helped to reduce the crack face separation and provide internal heating to accelerate the healing kinetics.

Blaiszik et al. [20] demonstrated the influence of shell wall morphology on the microcapsule rupture based on the study carried out on PUF micro/nanocapsules containing a mixture of resin and solvent. The capsule shell wall was found to comprise of two distinct regions with a thin continuous inner shell wall of low molecular weight polymer that deposits at the oil-water interface formed by urea and formaldehyde reaction in aqueous phase, and a thicker rough exterior shell wall formed by coalesce the colloidal UF particles as the UF reaction progresses. When incorporating this microcapsule into epoxy matrix, the rough surface of the wall allowed a good adhesion to the epoxy matrix by increasing capsule fracture and healing agent delivery.

To provide a repair system with matching chemical entity with host epoxy matrix, researchers focused on the use of microcapsule encapsulated with epoxy and hardener. Yin et al. [22] developed a two-component healing system consisting of epoxy encapsulated PUF microcapsules $(30-70 \mu \mathrm{m})$ and a latent hardener dissolved in epoxy. When cracks were propagated through the composites, the damaged microcapsule released the epoxy. The latent hardener which is soluble in the matrix encountered with released epoxy from the broken microcapsules to recover the crack upon curing at $130-180^{\circ} \mathrm{C}$.

Yuan and coworkers $[24,43]$ developed a self-healing epoxy system by incorporating both epoxy loaded and mercaptan loaded microcapsules. The size distributions of epoxy-loaded and hardener-loaded PMF capsules are shown in Figure 5a. This two-component self-healing epoxy with stoichiometric weight ratio (i.e. 1.26) of epoxy to mercaptan capsules offered maximum self-healing at or below room temperature with crack healing chemistry similar to the matrix polymer (Figure 5b). As the cracks propagate through the matrix, both type microcapsules fractured and successively released their contents. In the cracked surface, the epoxide groups quickly reacted with mercaptan in the presence of catalyst benzyldimethylamine to recover the matrix. The high flowability, fast consolidation and miscibility of the released epoxy and mercaptan facilitated rapid repair.
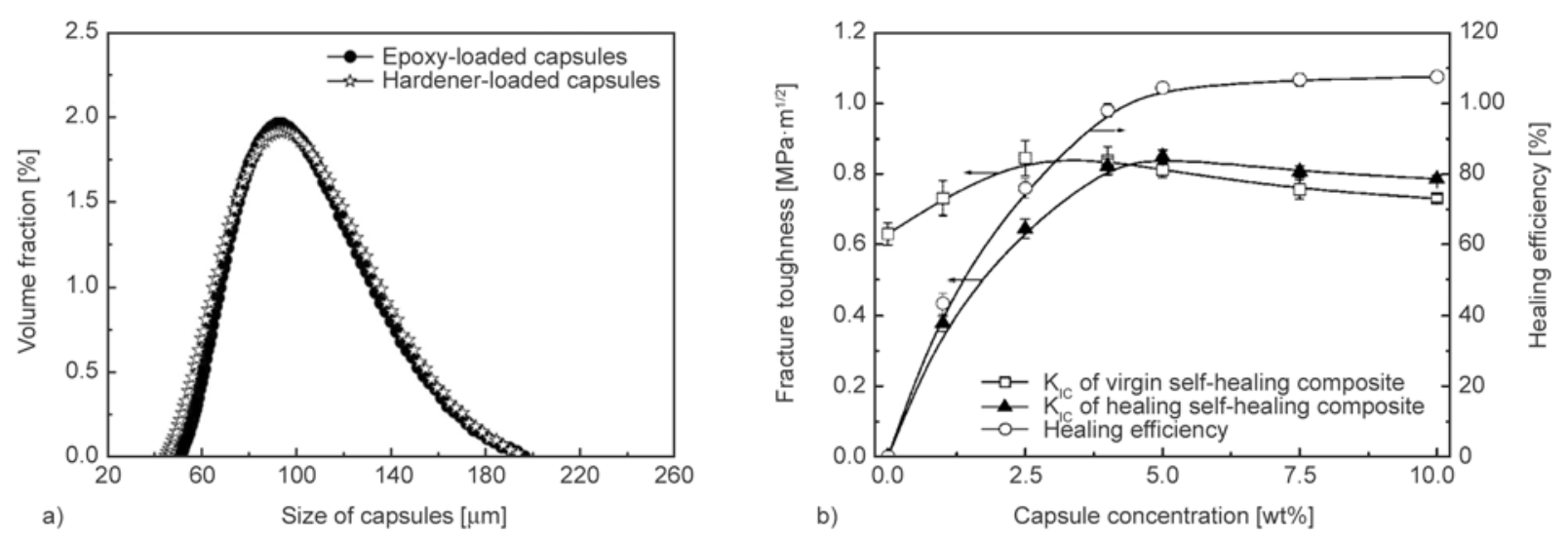

Figure 5. a) Size distribution of epoxy-loaded capsules and hardener-loaded capsules and b) influence of capsule concentration on fracture toughness and healing efficiency. Weight ratio of the two types of capsules in all the self-healing

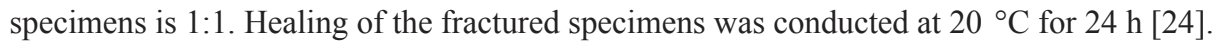


Later, a two component epoxy self-healing system based on epoxy-amine healing chemistry was developed [26]. Both epoxy encapsulated capsules (produced by in situ polymerization) and amine encapsulated capsules (produced by the vacuum infiltration) in optimal ratio were incorporated into epoxy matrix. The reaction of epoxy and amine released from the respective capsules healed the damaged area. The healed fracture surfaces revealed that the healed matrix failed cohesively which indicated the in situ formation of epoxy and good bond strength to the matrix.

In recent studies, poly(methylmethacrylate) (PMMA) was chosen as the capsule shell as it has superior stability, biocompatibility and good compatibility with epoxy. Both one component PMMA microcapsules [27] and two component PMMA microcapsules [44] were investigated. The one component system [27] was designed in such a way that the released curing agent (polyetheramine) upon rupture of the PMMA shell crosslinked with the residual epoxy groups to form the new thermoset region in the original matrix interface. They found that the healing efficiency of the two-components system was higher than that of the single component self-healing system due to fast reaction occurred between the resin and the hardener leaked from the microcapsule to the crack surface. The effect of weight ratios of epoxy-/hardenercontained microcapsules on the healing efficiencies of epoxy composites was also investigated. It was observed that the self-healing efficiency significantly increased with increasing microcapsules content from 5 to $15 \mathrm{wt} \%$. Increased microcapsule content helped to release enough epoxy and hardener to heal the cracks.

Very recently, nanocontainers with copolymer shell walls were developed as the functional copolymers containing oxirane function to match the epoxy structure as well as a second monomer to create fragility to fracture under crack [45]. Nanocontainers encapsulated with amine healing agent were prepared using poly (glycidylmethacrylate-co-methylmethacrylate) [poly(GMA-co-MMA)] via double emulsion technique.

The dual microcapsules were also used in glass fiber reinforced epoxy composites and studied the selfhealing action upon low velocity impact damage [46]. Epoxy encapsulated PUF microcapsules (produced via in situ polymerization) and amine hardener encapsulated PUF microcapsules (produced via vacuum infiltration method) were properly mixed with epoxy in the ratio 10:3. Appropriate fabrication technique via hand layup followed by vacuum bag molding confirmed the protection of microcapsules in this glass fiber reinforced composite. In the crack area, the bleeding from microcapsules recovered the damaged area by formation of new bond.

As the weakest region in fiber reinforced polymer composite, the fiber/matrix interphase should require preferential self- repairing action [47]. The knowledge gained on bulk self-healing has also been transferred to the fiber/matrix interphase. Carbon fiber/ epoxy interphases [48] and glass fiber/epoxy interphases [49] were functionalized with capsules containing reactive epoxy resin and ethyl phenyl acetate solvent to provide the interfacial self-healing upon debonding of the fiber/matrix interface.

During the progress of research in self-healing epoxy, scientists discovered methods to compensate the reduction in elastic modulus and hardness of the epoxy due to the presence of microcapsule by incorporating carbon nanotubes (CNTs), which was proved to improve the aforementioned values significantly [50]. Table 1 tabulated the healing efficiency obtained for epoxy composites with different polymer capsules.

\subsection{Polymer capsules in epoxy coatings}

The self-healing concept was also applied in epoxy coating besides in epoxy composites structures. Protective self-healing epoxy coatings are developed by incorporating containers, which are able to release a corrosion inhibitor or self-healing agents under the situations like $\mathrm{pH}$ changes caused by the triggering situations like start of corrosion process, ionexchange process, and mechanical damage. Stankiewicz et al. [51] reviewed different type of self-healing coating for anti-corrosion applications. Drying oil encapsulated capsules such linseed oil encapsulated phenol-formaldehyde (PF) microcapsules [52] and tung oil encapsulated PUF microcapsules [53] were used to make self-healing epoxy coatings. Drying oils are chemically unsaturated glycerides of long chain fatty acids. When these oils contact with oxygen, carbon-carbon chain cleaved to polymerize and the degree of double bond unsaturation controls the polymerization rate. The linseed oil and tung oil released from microcapsules polymerized when contact with the air to heal the scratched area. Even though the chemical nature, physical and mechani- 
Table 1. The healing efficiency reported for different type of containers

\begin{tabular}{|c|c|c|c|c|c|}
\hline No. & Matrix & Containers & Self-healing agent & Self-healing efficiency & Ref. \\
\hline 1 & Epoxy & PUF & Encapsulated DCPD/Grubbs catalyst & $85 \pm 5 \%$ at room temperature & {$[36]$} \\
\hline 2 & Epoxy/carbon fiber & PUF & Encapsulated DCPD/Grubbs catalyst & $\begin{array}{l}45 \% \text { at room temperature } \\
80 \% \text { at } 80^{\circ} \mathrm{C}\end{array}$ & {$[37]$} \\
\hline 3 & Epoxy & PUF & Encapsulated chlorobenzene & $82 \%$ at room temperature & [19] \\
\hline 4 & Epoxy & PUF & $\begin{array}{l}\text { Encapsulated phenyl acetate/ethyl phenyl } \\
\text { acetate }\end{array}$ & $100 \%$ at room temperature & {$[39]$} \\
\hline 5 & Epoxy & PUF & Encapsulated epoxy/latent hardener & $111 \%$ at $130-180^{\circ} \mathrm{C}$ & [22] \\
\hline 6 & Epoxy & PMF & $\begin{array}{l}\text { Encapsulated epoxy/Encapsulated mercaptan } \\
\text { based hardener }\end{array}$ & $104 \%$ at $20^{\circ} \mathrm{C}$ & {$[24]$} \\
\hline 7 & Epoxy & PUF & $\begin{array}{l}\text { Encapsulated epoxy (by in situ polymeriza- } \\
\text { tion)/encapsulated amine hardener (by vacuum } \\
\text { infiltration) }\end{array}$ & $91 \%$ at room temperature & {$[26]$} \\
\hline 8 & Epoxy & PMMA & $\begin{array}{l}\text { Encapsulated epoxy/encapsulated amine hard- } \\
\text { ener }\end{array}$ & $84.5 \%$ at room temperature & {$[44]$} \\
\hline 9 & Epoxy/glass fiber & PUF & $\begin{array}{l}\text { Encapsulated epoxy (produced via in situ poly- } \\
\text { merization)/encapsulated amine hardener (pro- } \\
\text { duced via vacuum infiltration) }\end{array}$ & $40 \%$ at room temperature & {$[46]$} \\
\hline 10 & Epoxy & GMA-co-MMA & Encapsulated amine hardener & $85 \%$ at room temperature & {$[45]$} \\
\hline 11 & Epoxy & Electrospun PAN mats & Immersed epoxy/immersed amine & $38 \%$ at room temperature & [61] \\
\hline 12 & Epoxy & HGBs & Loaded epoxy/loaded amine & $62 \%$ at $50{ }^{\circ} \mathrm{C}$ & {$[69]$} \\
\hline
\end{tabular}

cal characteristics of healed area are not the same as the matrix, the authors claimed that the creation of a barrier between air and surface could increase the life cycle of the coating. The corrosion resistance studies by electrochemical impedance spectroscopy (EIS) showed a better preservation of corrosion resistance of epoxy coating incorporated with tung oil encapsulated PUF microcapsule.

The encapsulated epoxy microcapsules were incorporated into epoxy paint composed of epoxy and modified polyamide hardener to prepare self-healing coating for carbon steel [23]. The capsules were ruptured along with the damage on the coating and the stored epoxy resin released into the matrix. The released epoxy polymerized when contacting with the residual polyamide hardener after curing of the epoxy in matrix, to repair the scratch. The EIS studies were used to evaluate the self-healing activity of epoxy microcapsules filled epoxy coating on carbon steel. These microcapsules were found to heal the scratched coating surface in a short time. Coating with an optimum concertation of epoxy microcapsules $(20 \mathrm{wt} \%)$ completely healed the scratched surface with in $4 \mathrm{hrs}$. Also, these epoxy microcapsules were later used in epoxy/polyamide coatings for mild carbon steel for self-healing performance along with polyaniline nanofibers for passive property [54].

In epoxy protective coatings, solvents used to lower resin viscosity and heat treatment used to remove solvent or to cure coating matrix adversely affect the sta- bility of the microcapsules. Hence solvent and thermal resistant microcapsule are practically required for self-healing epoxy coatings. A novel doublelayered polyurea microcapsules containing hexamethylene diisocyanate (HDI) with excellent shell tightness synthesized via interfacial polymerization reaction showed good resistance to temperature and nonpolar solvents [55]. These HDI encapsulated double-layered polyurea microcapsules showed outstanding anticorrosion performance through selfhealing functionality of the released HDI in damaged locations.

The epoxy coating loaded with these multilayer composite microcapsules based on Pickering emulsion had excellent anticorrosive and self-healing performance. This was confirmed from the optical images of the scratched coating with and without microcapsule loading (Figure 6). This cheaper and greener approaches adopted for the self-healing technology pave way for further use in industrial and environmental fields.

\section{Polymer fibers as self-healing agent containers}

Polymer fibers were also found as effective healing agent containers in epoxy matrix. Different methods were adopted to encapsulate the healing agents inside these polymer fibers including coelectrospinning [56-58], emulsion electrospinning [56] and emulsion solution blowing [56]. DCPD enwrapped into polyacrylonitrile (PAN) using coelectrospin- 


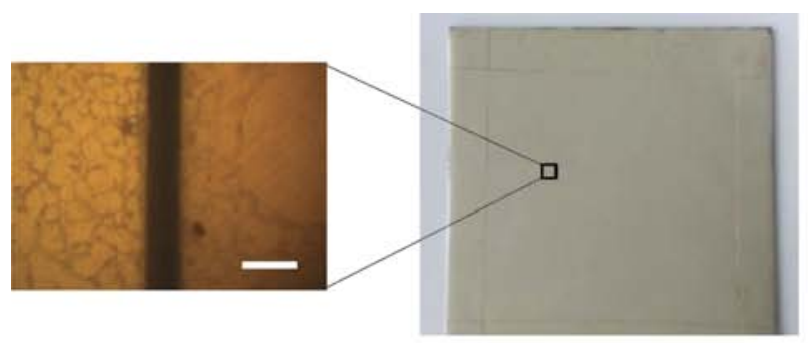

a)

$\left(A_{1}\right)$

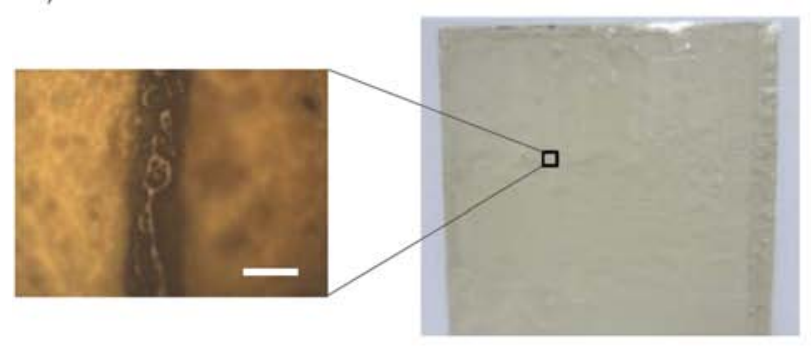

b)

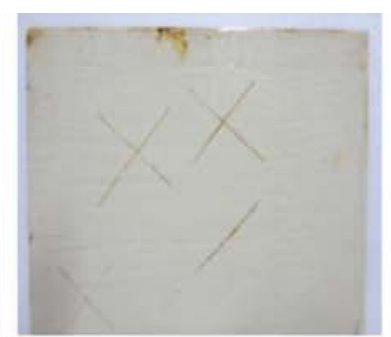

$\left(A_{2}\right)$

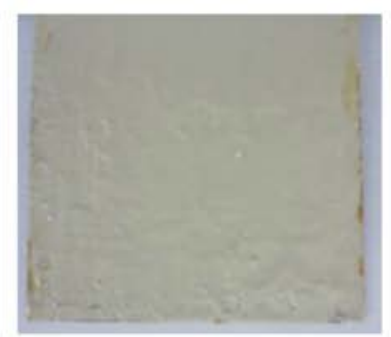

$\left(B_{2}\right)$

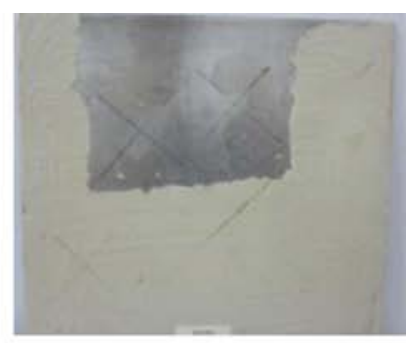

$\left(A_{3}\right)$

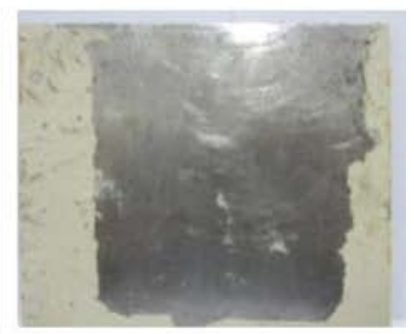

$\left(B_{3}\right)$

Figure 6. Brine-submersion corrosive-accelerating test. Photograph of steel plates coated with common coating (Group A) and multilayer microcapsules based on Pickering emulsion -embedded self-healing coating (Group B): $\left(A_{1}, B_{1}\right)$ before, $\left(A_{2}, B_{2}\right)$ after submersed in $10 \mathrm{wt} \% \mathrm{NaCl}$ solution for $120 \mathrm{~h}$, and $\left(\mathrm{A}_{3}\right)$ traces of corrosion on steel plate, $\left(\mathrm{B}_{3}\right)$ anticorrosive performance of self-healing coating on steel plate. OM images of enlarged view of scratched region on (a) common coating and (b) self -healing coating, the scale bars are $200 \mu \mathrm{m}$. The steel plates $\left(10 \times 10 \mathrm{~cm}^{2}\right)$ were submerged in $\mathrm{NaCl}$ solution $(10 \mathrm{wt} \%)$ for $120 \mathrm{~h} \mathrm{[29]}$.

ning to form core-shell DCPD/PAN nanofibers [56, 57]. The electrospinning was carried out in a labmade coaxial needle setup for generating the coreshell jet $[59,60]$ by supplying a solution of $10 \mathrm{wt} \%$ PAN in dimethyl formamide (DMF) as the outer jet (shell) and the solution of $10 \mathrm{wt} \%$ DCPD in DMF as the inner jet (core). Self-healing carbon-fiber/epoxy composites were developed by incorporating this core-shell DCPD/ PAN nanofibers at laminate interfaces. Epoxy monomer was also encapsulated within a poly(vinyl alcohol) (PVA) nanofiber using coelectrospinning [58]. Thus obtained core-shell epoxy/ PVA nanofibers was found to be stable enough within the curing epoxy matrix.

In a different approach, as-electrospun mats of polyacrylonitrile (PAN) containing both epoxy and amine as healing solutions were embedded into an epoxy matrix [61]. Here, the healing agents were not subjected to encapsulation or electrospinning process as in the previous case and hence this technique could be implemented to carry reactive healing agents without tedious process. The electrospun PAN mats were simply immersed in liquid epoxy solution or diethylenetriamine (DETA) and were alternatively layered up in epoxy composite structure. Thus generated composites structures achieved multiple healing cycles. This method open up a way to the mass production of self-healing composites for structural applications.

\section{Hollow glass fibers (HGF) and hollow glass bubbles (HGB) as self-healing agent containers}

The high chemical inertness as well as thermal stability of hollow glass based self-healing containers offers advanced self-healing technology which can eliminate the limitations of corrosive feature of some healing agents and thermally degradability of the shell. The hollow glass fibers can be used as an ideal medium for storing healing components together with exploring them as structural reinforcing agents in advanced epoxy composite structures [62-65]. Hollow glass fibers with external diameter of $60 \mu \mathrm{m}$ and $50 \%$ hollow fraction was used by Pang and Bond [62] to restore the healing components. They incorporated the unidirectional hollow glass fibers in epoxy matrix with $0^{\circ} / 90^{\circ}$ lay-up. A significant fraction of flexural strength lost after impact damage was found to be restored by the self-healing action of resin and hardener stored within hollow fibers. The self-healing mechanism operates in this systems is similar to bleeding mechanism in biological organisms. During a damage event, healing agent passed from within any broken hollow fibers infiltrated the damage area. 
These HGF were also incorporated into carbon fiber reinforced epoxy in order to impart the self-healing ability to carbon fiber reinforced polymer (CFRP) laminates used in aerospace applications [66]. It was found that the presence of HGF within a CFRP laminate produce minimal degradation in flexural strength and ply disruption. Recently, much thinner hollow glass fibers (13 $\mu$ m outer diameter) were used in a damage-detecting and self-repairing epoxy composite to ensure major reinforcement [67]. Self-repair in this system was achieved by adding polyester resin (catalyzed resin and initiator) to the hollow fibers. When compared to the filled-damaged specimens, the healed specimens had 20 and $26 \%$ higher bending strength and bending modulus respectively.

Etched HGB are found to be another stable container for amine curing agent. Etched HGB with holes at the micrometer level were fabricated by etching the glass bubbles using dilute hydrofluoric acid (HF) in specially designed mixer. [68]. Etched HGB in micrometer range (diameter $66.9 \pm 8.2 \mu \mathrm{m}$, and shell thickness $0.79 \pm 0.41 \mu \mathrm{m}$ ) were used to encapsulate both epoxy resin and the amine hardener [69]. The healing agents inside the HGB survived from the manufacturing process and following 24 hour of cure. These healing agent containers were incorporated in the optimized ratio of 4:1 for epoxy loaded HGBs to amine loaded HGBs to get better selfhealing performance.

\section{Inorganic nanomaterials as self-healing agent containers}

When compared with tedious encapsulation process required in the case of most of the polymer capsules, merely 'physical' encapsulation generally vacuum infiltration is required in the case of these inorganic nanomaterials which make this self-healing technique more demanding to heal the micro-crack. Even though there are some reports on the use of inorganic nanoporous and nanotubes as self-healing containers, still more detailed investigations are required in this area. Like polymer capsules, the inorganic containers also offer mechanical reinforcement apart from the healing agent loading and magnitude of reinforcement in most cases much higher than that offered by the polymer capsules. Moreover, the compatibility of the inorganic nanomaterials with epoxy is well understood.

Kirk et al. [70] encapsulated both epoxy and hardener separately inside channels of nanoporous silica using infiltration method. The feasible self-healing approach for the recovery of mechanical properties of epoxy by adding a mixture of epoxy filled nanoporous silica capsules and hardener filled nanoporous silica capsules were proposed by them. In their study, they observed only a partial self-healing, because the amount of healing agents inside the capsule was not large enough to heal large macro cracks analyzed. Hence they claimed the effective use of such selfhealing containers for preventing/healing microcracks which are the precursor to macrocrack formation/extension.

Another promising 'green' nanocontainer for healing agents is naturally occurring halloysite nanotube (Figure 7). Halloysite is a two-layered aluminosilicate clay mineral and is available cheaply in thousands of tons from natural deposits. Depending on the deposit, the size of halloysite nanotubes (HNT) vary within $1-15 \mu \mathrm{m}$ of length and $10-150 \mathrm{~nm}$ of inner diameter [71].

Halloysite can readily dispersed in epoxy without any surface treatment. It was reported that the halloysite nanotubes could act as impact and toughness modifier for epoxy [72, 73]. Abdullayev and Lvov $[74,75]$ reviewed the use of halloysite clay nanotubes for controlled release of protective agents for medical and pharmaceutical applications, anticorrosive and self-healing coatings etc.

Melo et al. [76] encapsulated solvents inside the halloysite lumen and they investigated the feasibility to use them for developing self-healing epoxy. After the insertion of the solvent (DMSO) inside HNT using vacuum infiltration, additional encapsulation using polyelectrolytes was done to block the ends of the HNT in order to trap the solvent inside the structure (Figure 8). This solvent encapsulated HNT can be effectively used in epoxy to make it self-healing in the future. Generally, high molecular weight substances like polymers (epoxy resin) have slow release time due to their stronger adsorption to the halloysite surface. This stronger adsorption is expected due the fact that the high molecular weight substances have more functional groups that can interact with $\mathrm{OH}$ groups in halloysite surface to establish hydrogen bonding. Hence no need for additional encapsulation in such case [74].

For self-healing coatings, the corrosion inhibitors are usually loaded as the healing agent inside the nanocontainers. Halloysite nanotubes were successfully used as container for corrosion inhibitor for paints 


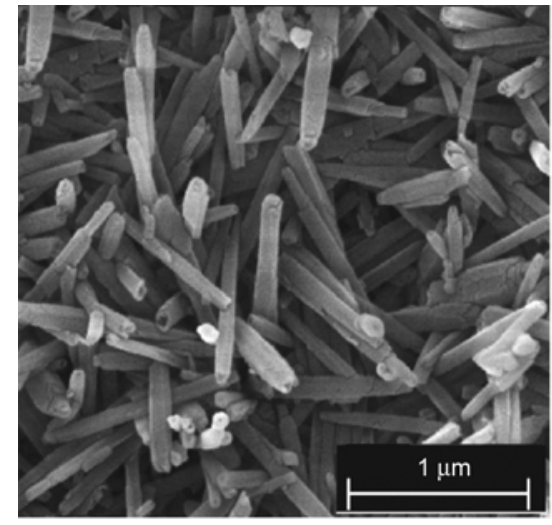

a)

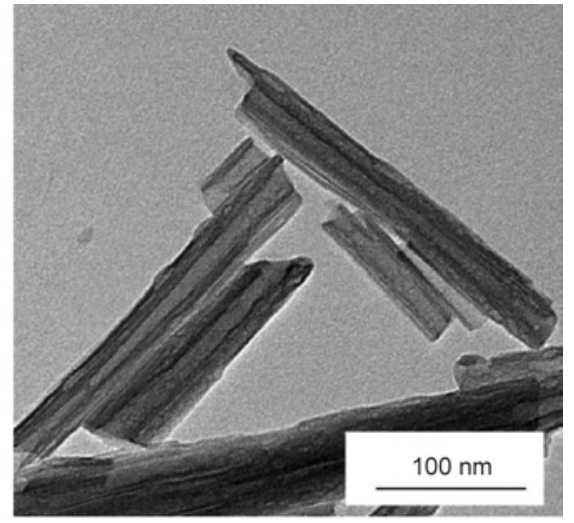

b)

Figure 7. (a) SEM and (b) TEM images of halloysite nanotubes [78]

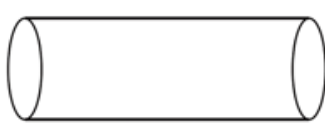

Halloysite nanotube

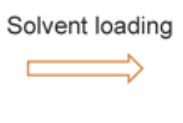

Halloysite nanotube filled with solvent

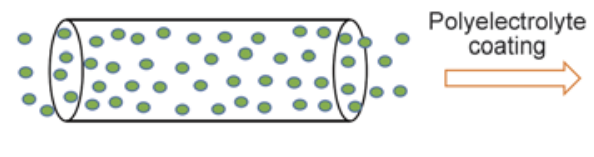

Figure 8. Encapsulation process of solvent into HNTs [76]

[77] and acrylic and polyurethane coatings [78]. While the halloysite inner void loaded with the corrosion inhibitor, the outer surface was covered with polyelectrolyte multilayers. The polyelectrolyte multilayers are sensitive to changes in the surrounding environment. The opening of the polyelectrolyte layer with $\mathrm{pH}$ changes resulted in occasional release of inhibitor in local corrosion areas. Once the corrosion area is healed, the $\mathrm{pH}$ shifted to its original value which could stop the release of corrosion inhibitor by closing the polyelectrolyte shell.

The similar corrosion inhibitor loaded halloysite nanotubes will be a promising candidate to generate self-healing anticorrosive epoxy protective coating for metals. Mesoporous silica was also used to load corrosion inhibitors for sol-gel protective coating for metal [79].

Maia et al. [80] adopted a one step process including synthesis of silica nanocapsules (SiNC) and loading of corrosion inhibitor 2-mercaptobenzothiazole (MBT) which outlook the mass production. This process route provided silica nanocontainers with an empty core and shell with gradual mesoporosity, which facilitates better loading efficiency and prolonged and stimuli-triggered release of the inhibitor. When incorporating these loaded silica nanocapsules into water-based epoxy system to coat aluminium alloy, the SiNC release a higher amount of $\mathrm{MBT}$ in acidic $\mathrm{pH}$ and at high concentrations of
$\mathrm{NaCl}$. This facilitated prolonged self-healing for long time in corrosive media.

Epoxy coatings containing corrosion inhibitor (MBT) loaded mesoporous silica was proved to have selfhealing properties [81]. It was showed that epoxy coating with $4 \mathrm{wt} \%$ MBT loaded mesoporous silica had partial recovery from artificially created defects as shown by it response to EIS analysis when exposed to $3.5 \mathrm{wt} \% \mathrm{NaCl}$ solution. Although a decrease in impedance values in the low-frequency range was observed during the first day, impedance values increased after 24 hours of immersion (Figure 9).

Moreover, the inherent corrosion protection capability of halloysite nanotubes and silica nanoparticles [82] will be an added advantage for epoxy coating incorporated with these inorganic materials loaded with corrosion inhibitors. Previously, it was shown that HNTs enhanced the corrosion protection capability of epoxy coating for a carbon steel substrate along with nanozinc dust [83].

Above all, the dimension of the epoxy monomer (diglycidyl ether of bisphenol A) (as per the molecular dynamic simulation studies) [84] is suitable to be loaded even inside the pores in meso-scale. Suzuki et al. [85] showed that the pore size in mesoporous silica $(\sim 4 \mathrm{~nm})$ is sufficiently large enough for epoxy polymers $(\sim 0.5 \mathrm{~nm})$ to penetrate into the internal mesospace. Hence, it is feasible to insert the epoxy monomers into the mesopores and nanotubes due to capillary force. 

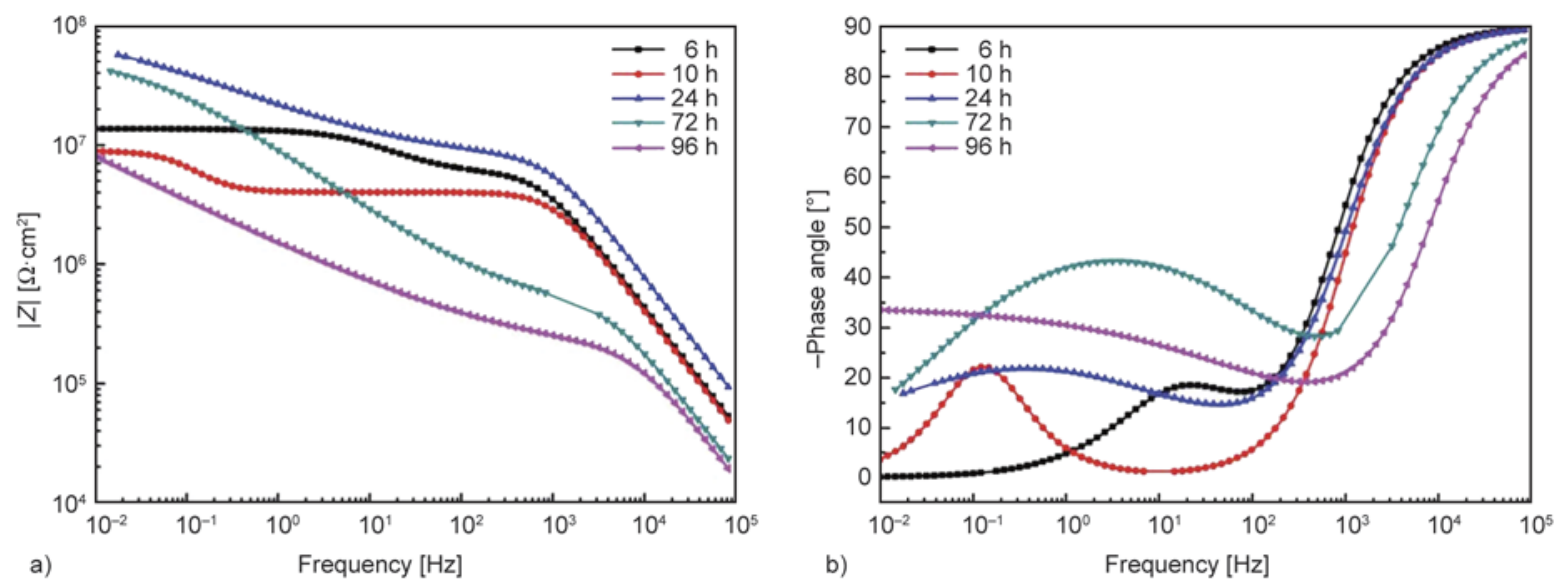

Figure 9. Electrochemical impedance spectroscopy bode plots of epoxy- $4 \mathrm{wt} \%$ silica-MBT coating after artificial defect exposure to $0.1 \mathrm{~mol} \cdot \mathrm{L}^{-} 1 \mathrm{NaCl}$ solution [81]

\section{Carbon nanotubes (CNT) as containers for self-healing agents}

The ability of carbon nanotubes to act as reservoirs for the self-healing agents has been investigated. As a primary research in this area, Lanzara et al. [86] studied the feasibility of using CNTs as containers for healing agents by understanding the molecular dynamics (MD) of a fluid which resembles an organic healing agent leaking out of a damaged single-walled CNT. As the crack propagates through the matrix the following would happen, (1) a CNT nanocontainer which would first slow down crack propagation, (2) then release the healing agent as the outer wall of the CNT is damaged and (3) finally CNT would seal back. This MD simulation suggested a new way of using carbon nanotubes as a reinforcing self-healing reservoir that have the potential to reduce the damage through the host matrix, selfrepair the crack and at the same time strengthen the material before and after the repairing process.

Later, Sinha-Ray et al. [56] loaded the healing agents like DCPD and isophorone diisocyanate into CNTs by using self-sustained diffusion method. In this method, CNTs were blended with dilute solution of self-healing agents in benzene by means of sonication and the Fickian diffusion of healing agent equilibrate the healing agent concentration inside CNTs with that in the bulk. In order to avoid a halt in the intercalation process at this low solute concentration inside CNTs, the solution with suspended CNTs was left to evaporate. The bulk concentration of solute gradually increased due to the solvent lost and this permanently sustained the Fickian diffusion of the solute into CNTs, which allowed complete filling of the CNT bore. The TEM images of CNT samples intercalated with DCPD and isophorone diisocyanate (Figure 10) showed that the filled CNT with the healing agents. The amorphous turbostratic CNTs used in this work could be easily broken as evident form the partially broken wall by the sonication process (Figure 10b), which confirmed the possible release of the healing agents as formation of defect.

\section{Combination of containers for}

\section{self-healing epoxy composites and coating}

Researchers utilized the combined benefit of different containers so as to achieve advanced self-healing ability. Encapsulated polymer and inorganic capsules are used together in epoxy matrix for the strength restoration [87]. Hollow silica capsules encapsulated with an instant hardener (antimony pentafluoride) in the form of antimony pentafluorideethanol complex and epoxy monomer encapsulated by PMF were incorporated into epoxy matrix. This system could effectively healed within few seconds and about $8.3 \%$ impact strength was recovered after $20 \mathrm{~s}$. Within a healing time of $100 \mathrm{~s}$, this system could reached its maximum healing efficiency (Figure 11).

PUF microcapsules loaded with epoxy and etched hollow glass bubbles (HGBs) loaded with amine were simultaneously used to produce self- healing epoxy composite [88]. The amount and the mass ratio of the released healing agents at the damaged area were found to depend on parameters like size, content and core capacity of the healing agent containers. The longest diffusion distance from their carriers is also critically influence the self-healing 


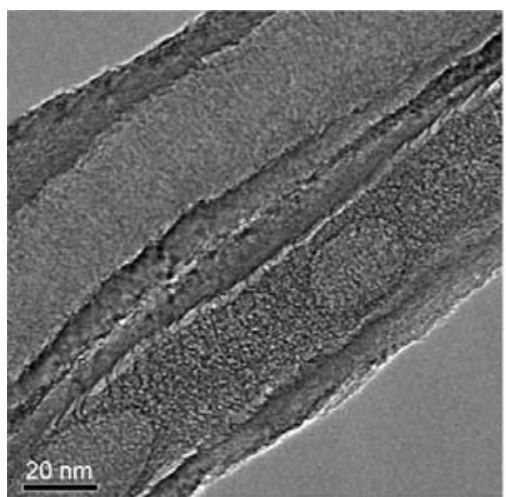

a)

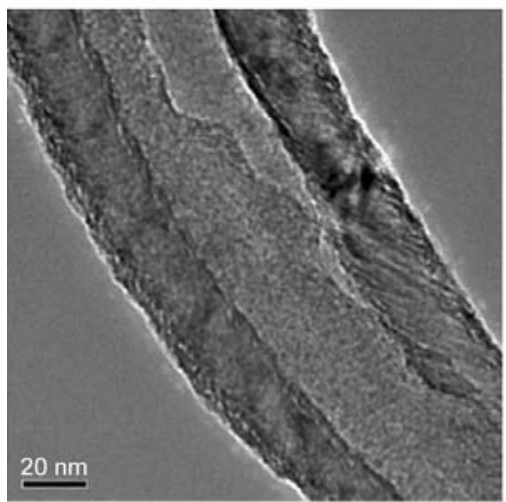

c)

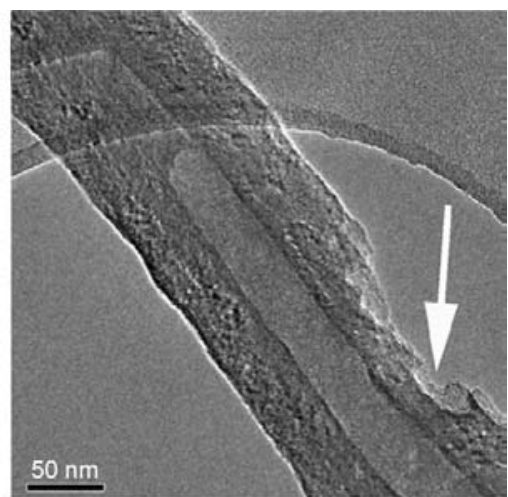

b)

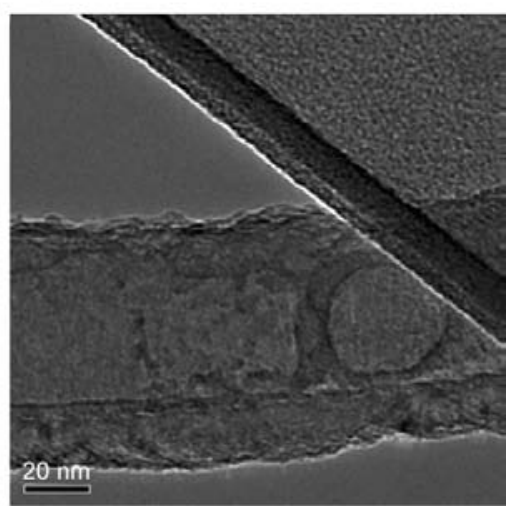

d)

Figure 10. TEM images of the intercalated self-healing materials inside CNTs. Panels (a) and (b) show DCPD inside CNTs, while (c) and (d) show isophorone diisocyanate inside CNTs. In panel (b) the arrow indicates the partially broken CNT wall [56]

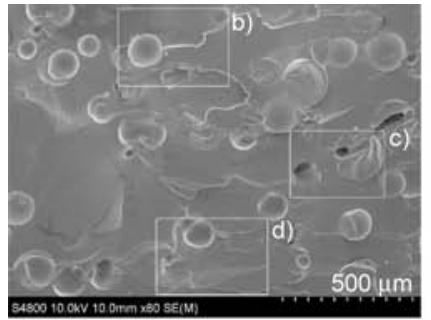

a)

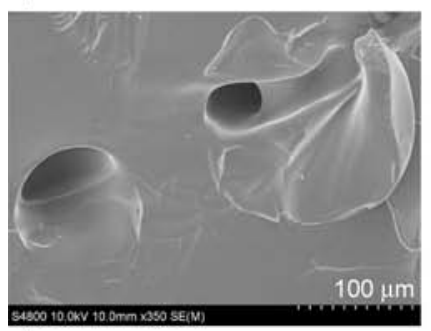

c)
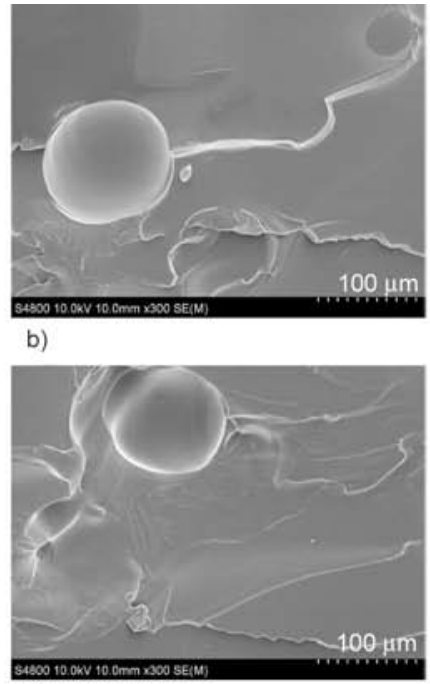

d)

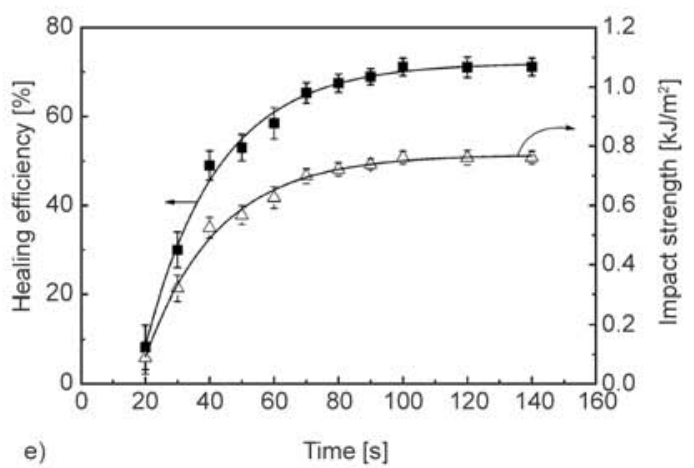

Figure 11. (a) SEM image of impact fracture surface of healed self-healing epoxy matrix with hardener encapsulated silica capsules and epoxy encapsulated PMF. The specimen had been fractured by the first impact test, healed at $25^{\circ} \mathrm{C}$ for $100 \mathrm{~s}$, and then fractured again by the second impact test. (b-d) Magnified views of different parts of (a): (e) healing efficiency versus healing time of self-healing specimens determined by impact test [87].

process in the two-part system. With a shorter diffusion distance at higher concentrations and efficient mixing lead to an improved healing performance.

\section{The role of container parameters on self- healing performance of epoxy}

One of the most important factors which affects the self-healing performance of epoxy system is the 
easiness in releasing the healing agent upon damage and this in turn depends on the thickness of the container walls, container composition and container core composition. Researchers used characteristic techniques such as Fourier transform infrared spectroscopy, scanning electron microscopy, particle size analyzer for evaluating these parameters of the capsules. Both the size and weight fraction of the microcapsule control the amount of healing agent released in the damaged plane and hence the degree of self-healing achieved. At a given weight fraction, larger microcapsules produce superior healing performance because the release of more healing agent per unit crack area [89]. Encapsulation of containers can be verified quantitatively and qualitatively by Fourier transform infrared analysis, X-ray diffraction, Brunauer-Emmett-Teller (BET) surface area, thermogravimetry and SEM.

Moreover, the competition between polymerization kinetics and crack increase rate is one of the factors for effective self-healing [90]. It was reported that a significant crack arrest and life-extension occurred when the healing rate is more than the growth rate of the damage. The effect of healing agent encapsulated microcapsule on epoxy cure kinetics was investigated [91]. The mechanism (autocatalytic) of epoxy cure reaction was found to be unaltered by the presence of the healing components responsible for the introduction of healing functionality such as resin encapsulated PUF and amine hardener immobilized on a mesoporous siliceous substrate.

\section{Conclusions}

The high cost of active monitoring and external repairing in epoxy structural materials can be better eliminated by introducing self-healing ability in them [92], for example corrosion cost reached $4.2 \%$ of the gross national product (GNP) of a country for 12 national surveys up to 2010 [93]. Similarly, the large economic concerns raised by corrosion of metallic structures, forces the researchers to search for cost effective self-healing coatings. With proper selection of containers, it could be possible to develop robust, cost-effective and highly efficient epoxy self-healing technologies so as to offer better service life to protective coatings, construction, aerospace, and electronics structures. The introduction of less expensive and possible green healing components in epoxy self-healing coating and composites material were reported. The use of catalyst free healing agents like solvents, epoxy resins etc. were developed in search for cost reduction. Due to the difficulty in encapsulating the amine hardener inside the common polymer capsules like PUF and PMF, PMMA based capsules loaded with epoxy and amine hardener can be a better choice to maintain the epoxy chemistry in the damage area even after the recovery. The novel preparation methods based on Pickering emulsion to achieve solid particle stabilized microcapsules and miniemulsion techniques to achieve the polymer nanocapsules are found to be promising in the area.

The ease of availability, better response to submicron crack, the easy penetration of epoxy monomer into the nano/meso pore and the ability to enhance the matrix properties are the advantages of the inorganic nanotubes as healing agent container for epoxy. Along with the capability to store the healing agent possessed by these inorganic nanomaterials, the inherent corrosion protection ability and their contribution to mechanical reinforcement to the matrix makes them a promising candidate as selfhealing containers for developing multifunctional epoxy for structural composites and coating. For developing economically viable self-healing technology, along with the use of low-cost healing agents, the exploitation of readily available, cheaper and green containers like halloysite $[94,95]$ and nanoclay or lignin nanoparticle-stabilized Pickering emulsion templates are promising. Even though the studies are in the preliminary stage, the capability of CNT can also be effective as containers in epoxy selfhealing technology. Moreover, the use of low cost lab-made electrospinning techniques open up promising future for the self- healing technology.

$\begin{array}{ll}\text { Abbreviations } & \\ \text { CFRP } & \text { Carbon fiber reinforced polymer } \\ \text { CNT } & \text { Carbon nanotube } \\ \text { DCPD } & \text { Dicyclopentadiene } \\ \text { DETA } & \text { Diethylenetriamine } \\ \text { DMF } & \text { Dimethyl formamide } \\ \text { DMSO } & \text { Dimethyl sulfoxide } \\ \text { EDA } & \text { Ethylenediamine } \\ \text { EIS } & \text { Electrochemical impedance spectroscopy } \\ \text { GNP } & \text { Gross national product } \\ \text { HDI } & \text { Hexamethylene diisocyanate } \\ \text { HGB } & \text { Hollow glass bubbles } \\ \text { HGF } & \text { Hollow glass fibers } \\ \text { HNT } & \text { Halloysite nanotubes } \\ \text { IPDI } & \text { Isophorone diisocyanate }\end{array}$




$\begin{array}{ll}\text { MBT } & \text { 2-mercaptobenzothiazole } \\ \text { MD } & \text { Molecular dynamics } \\ \text { MUF- } & \text { Melamine-urea-formaldehyde } \\ \text { PAN } & \text { Polyacrylonitrile } \\ \text { PAN } & \text { Polyacrylonitrile } \\ \text { PLLA } & \text { Poly(L -lactide) } \\ \text { PMF } & \text { Poly(melamine-formaldehyde) } \\ \text { PMMA } & \text { Poly(methylmethacrylate) } \\ \text { Poly(GMA-co-MMA) } & \text { Poly(glycidylmethacrylatemethylm- } \\ & \text { ethacrylate) } \\ \text { PUF } & \text { Poly(urea-formaldehyde) } \\ \text { PVAc } & \text { Poly(vinyl acetate) } \\ \text { PVA } & \text { Poly(vinyl alcohol) } \\ \text { PVCi } & \text { Poly(vinyl cinnamate) } \\ \text { PVF } & \text { Poly(vinyl formal) } \\ \text { ROMP } & \text { Ring-opening metathesis polymerization } \\ \text { SEM } & \text { Scanning electron microscopic } \\ \text { SiNC } & \text { Silica nanocapsules }\end{array}$

\section{Acknowledgements}

This review report was made possible by PDRA grant \# PDRA1-1216-13014 from the Qatar National Research Fund (a member of Qatar Foundation). The findings achieved herein are solely the responsibility of the authors.

\section{References}

[1] Pascault J-P., Williams R. J. J.: Epoxy polymers: New materials and innovations. Wiley-VCH, Weinheim (2010). DOI: $10.1002 / 9783527628704$

[2] Ellis B.: Chemistry and technology of epoxy resins. Springer, Berlin (1993).

[3] Afendi M., Abdul Majid M. S., Daud R., Abdul Rahman A., Teramoto T.: Strength prediction and reliability of brittle epoxy adhesively bonded dissimilar joint. International Journal of Adhesion and Adhesives, 45, 21-31 (2013).

DOI: $10.1016 /$ j.ijadhadh.2013.03.008

[4] Takahashi I., Ushijima M.: Detection of fatigue cracks at weld toes by crack detection paint and surface $\mathrm{SH}$ wave. Materials Transactions, 48, 1190-1195 (2007). DOI: 10.2320/matertrans.I-MRA2007845

[5] Mittal V.: Self-healing anti-corrosion coatings for applications in structural and petrochemical engineering. in 'Handbook of smart coatings for materials protection' (ed.: Makhlouf A. S. H.) Woodhead, Cambridge, 183, 197 (2014).

DOI: $10.1533 / 9780857096883.2 .183$

[6] Lamaka S. V., Zheludkevich M. L., Yasakau K. A., Serra R., Poznyak S. K., Ferreira M. G. S.: Nanoporous titania interlayer as reservoir of corrosion inhibitors for coatings with self-healing ability. Progress in Organic Coatings, 58, 127-135 (2007). DOI: $10.1016 /$ j.porgcoat.2006.08.029
[7] Hughes A. E., Cole I. S., Muster T. H., Varley R. J.: Designing green, self-healing coatings for metal protection. NPG Asia Materials, 2, 143-151 (2010).

DOI: 10.1038 /asiamat.2010.136

[8] White S. R., Sottos N. R., Geubelle P. H., Moore J. S., Kessler M. R., Sriram S. R., Brown E.N., Viswanathan S.: Autonomic healing of polymer composites. Nature, 409, 794-797 (2001).

DOI: $10.1038 / 35057232$

[9] Binder W. H.: Self-healing polymers: From principles to applications. Wiley-VCH, Weinheim (2010). DOI: $10.1002 / 9783527670185$

[10] Wool R. P.: Self-healing materials: A review. Soft Matter, 4, 400-418 (2008). DOI: $10.1039 / \mathrm{b} 711716 \mathrm{~g}$

[11] Yuan Y. C., Yin T., Rong M. Z., Zhang M. Q.: Self healing in polymers and polymer composites. Concepts, realization and outlook: A review. Express Polymer Letters, 2, 238-250 (2008). DOI: $10.3144 /$ expresspolymlett.2008.29

[12] Samadzadeh M., Boura S. H., Peikari M., Kasiriha S. M., Ashrafi A.: A review on self-healing coatings based on micro/nanocapsules. Progress in Organic Coatings, 68, 159-164 (2010). DOI: 10.1016/j.porgcoat.2010.01.006

[13] Wu D. Y., Meure S., Solomon D.: Self-healing polymeric materials: A review of recent developments. Progress in Polymer Science, 33, 479-522 (2008). DOI: 10.1016/j.progpolymsci.2008.02.001

[14] Yang Y., Urban M. W.: Self-healing polymeric materials. Chemical Society Reviews, 42, 7446-7467 (2013). DOI: $10.1039 / \mathrm{c} 3 \mathrm{cs} 60109 \mathrm{a}$

[15] Shchukin D. G.: Container-based multifunctional selfhealing polymer coatings. Polymer Chemistry, 4, 48714877 (2013). DOI: $10.1039 / \mathrm{c} 3$ py00082f

[16] Fayyad E. M., Al-Ali AlMa'adeed M., Jones A., Abdullah A. M.: Evaluation techniques for the corrosion resistance of self-healing coatings. International Journal of Electrochemical Science, 9, 4989-5011 (2014).

[17] Teixeira R. F. A., Hillewaere X. K. D., Billiet S., Du Prez F. E.: Chemistry of crosslinking processes for self-healing polymers. in 'Self-healing polymers' (Ed.: Binder W. H.) Wiley-VCH, Weinheim, 215-246 (2010). DOI: 10.1002/9783527670185.ch9

[18] Brown E. N., Kessler M. R., Sottos N. R., White S. R.: In situ poly(urea-formaldehyde) microencapsulation of dicyclopentadiene. Journal of Microencapsulation, 20, 719-730 (2003). DOI: $10.3109 / 02652040309178083$

[19] Caruso M. M., Delafuente D. A., Ho V., Sottos N. R., Moore J. S., White S. R.: Solvent-promoted self-healing epoxy materials. Macromolecules, 40, 8830-8832 (2007). DOI: $10.1021 / \mathrm{ma} 701992 \mathrm{z}$ 
[20] Blaiszik B. J., Caruso M. M., McIlroy D. A., Moore J. S., White S. R., Sottos N. R.: Microcapsules filled with reactive solutions for self-healing materials. Polymer, 50, 990-997 (2009).

DOI: $10.1016 /$ j.polymer.2008.12.040

[21] Suryanarayana C., Chowdoji Rao K., Kumar D.: Preparation and characterization of microcapsules containing linseed oil and its use in self-healing coatings. Progress in Organic Coatings, 63, 72-78 (2008)

DOI: 10.1016/j.porgcoat.2008.04.008

[22] Yin T., Rong M. Z., Zhang M. Q., Yang G. C.: Self-healing epoxy composites - Preparation and effect of the healant consisting of microencapsulated epoxy and latent curing agent. Composites Science and Technology, 67, 201-212 (2007).

DOI: 10.1016/j.compscitech.2006.07.028

[23] Liu X., Zhang H., Wang J., Wang Z., Wang S.: Preparation of epoxy microcapsule based self-healing coatings and their behavior. Surface and Coatings Technology, 206, 4976-4980 (2012).

DOI: $10.1016 /$ j.surfcoat.2012.05.133

[24] Yuan Y. C., Rong M. Z., Zhang M. Q., Chen J., Yang G. C., Li X. M.: Self-healing polymeric materials using epoxy/mercaptan as the healant. Macromolecules, 41, 5197-5202 (2008).

DOI: $10.1021 / \mathrm{ma} 800028 \mathrm{~d}$

[25] Yuan Y. C., Zhang M. Q., Rong M. Z.: The method to prepare microcapsules containing polythios (in Chinese). Chinese Patent 2007100299901, China (2007).

[26] Jin H., Mangun C. L., Stradley D. S., Moore J. S., Sottos N. R., White S. R.: Self-healing thermoset using encapsulated epoxy-amine healing chemistry. Polymer, 53, 581-587 (2012). DOI: $10.1016 /$ j.polymer.2011.12.005

[27] Li Q., Mishra A. K., Kim N. H., Kuila T., Lau K., Lee J. H.: Effects of processing conditions of poly(methylmethacrylate) encapsulated liquid curing agent on the properties of self-healing composites. Composites Part B: Engineering, 49, 6-15 (2013). DOI: 10.1016/j.compositesb.2013.01.011

[28] McIlroy D. A., Blaiszik B. J., Caruso M. M., White S. R., Moore J. S., Sottos N. R.: Microencapsulation of a reactive liquid-phase amine for self-healing epoxy composites. Macromolecules, 43, 1855-1859 (2010). DOI: $10.1021 / \mathrm{ma} 902251 \mathrm{n}$

[29] Yi H., Yang Y., Gu X., Huang J., Wang C.: Multilayer composite microcapsules synthesized by Pickering emulsion templates and their application in self-healing coating. Journal of Materials Chemistry A, 3, 13749 13757 (2015).

DOI: $10.1039 / \mathrm{C} 5 \mathrm{TA} 02288 \mathrm{~F}$

[30] Blaiszik B. J., Sottos N. R., White S. R.: Nanocapsules for self-healing materials. Composites Science and Technology, 68, 978-986 (2008).

DOI: $10.1016 /$ j.compscitech.2007.07.021
[31] Zhao Y., Fickert J., Landfester K., Crespy D.: Encapsulation of self-healing agents in polymer nanocapsules. Small, 8, 2954-2958 (2012).

DOI: $10.1002 / \mathrm{smll} .201200530$

[32] Lee J., Zhang M., Bhattacharyya D., Yuan Y. C., Jayaraman K., Mai Y. W.: Micromechanical behavior of self-healing epoxy and hardener-loaded microcapsules by nanoindentation. Materials Letters, 76, 62-65 (2012). DOI: 10.1016/j.matlet.2012.02.052

[33] Brown E. N., White S. R., Sottos N. R.: Microcapsule induced toughening in a self-healing polymer composite. Journal of Materials Science, 39, 1703-1710 (2004). DOI: 10.1023/B:JMSC.0000016173.73733.dc

[34] Brown E. N., White S. R., Sottos N. R.: Fatigue crack propagation in microcapsule-toughened epoxy. Journal of Materials Science, 41, 6266-6273 (2006). DOI: $10.1007 / \mathrm{s} 10853-006-0512-\mathrm{y}$

[35] Yuan L., Liang G-Z., Xie J-Q., Li L., Guo J.: The permeability and stability of microencapsulated epoxy resins. Journal of Materials Science, 42, 4390-4397 (2007). DOI: $10.1007 / \mathrm{s} 10853-006-0606-6$

[36] Brown E. N., Sottos N. R., White S. R.: Fracture testing of a self-healing polymer composite. Experimental Mechanics, 42, 372-379 (2002).

DOI: $10.1007 / \mathrm{BF} 02412141$

[37] Kessler M., Sottos N., White S.: Self-healing structural composite materials. Composites Part A: Applied Science and Manufacturing, 34, 743-753 (2003).

DOI: $10.1016 / \mathrm{S} 1359-835 \mathrm{X}(03) 00138-6$

[38] Noh H. H., Lee J. K.: Microencapsulation of self-healing agents containing a fluorescent dye. Express Polymer Letters, 7, 88-94 (2013). DOI: $10.3144 /$ expresspolymlett.2013.8

[39] Caruso M. M., Blaiszik B. J., White S. R., Sottos N. R., Moore J. S.: Full recovery of fracture toughness using a nontoxic solvent-based self-healing system. Advanced Functional Materials, 18, 1898-1904 (2008). DOI: $10.1002 / \mathrm{adfm} .200800300$

[40] Coope T. S., Mayer U. F. J., Wass D. F., Trask R. S., Bond I. P.: Self-healing of an epoxy resin using scandium(III) triflate as a catalytic curing agent. Advanced Functional Materials, 21, 4624-4631 (2011). DOI: $10.1002 /$ adfm. 201101660

[41] Neuser S., Michaud V., White S. R.: Improving solventbased self-healing materials through shape memory alloys. Polymer, 53, 370-378 (2012). DOI: $10.1016 /$ j.polymer.2011.12.020

[42] Neuser S., Michaud V.: Fatigue response of solventbased self-healing smart materials. Experimental Mechanics, 54, 293-304 (2014).

DOI: $10.1007 / \mathrm{s} 11340-013-9787-5$

[43] Yuan Y. C., Rong M. Z., Zhang M. Q., Yang G. C., Zhao J. Q.: Self-healing of fatigue crack in epoxy materials with epoxy/mercaptan system. Express Polymer Letters, 5, 47-59 (2011).

DOI: $10.3144 /$ expresspolymlett.2011.6 
[44] Li Q., Siddaramaiah, Kim N. H., Hui D., Lee J. H.: Effects of dual component microcapsules of resin and curing agent on the self-healing efficiency of epoxy. Composites Part B: Engineering, 55, 79-85 (2013). DOI: $10.1016 /$ j.compositesb.2013.06.006

[45] Khoee S., Kachoei Z.: Design and development of novel reactive amine nanocontainers for a self-healing epoxy adhesive: Self-repairing investigation using the lap shear test. RSC Advances, 5, 21023-21032 (2015).

DOI: $10.1039 / C 4 R A 16344 C$

[46] Chowdhury R. A., Hosur M. V., Nuruddin M., TcherbiNarteh A., Kumar A., Boddu V., Jeelani S.: Self-healing epoxy composites: Preparation, characterization and healing performance. Journal of Materials Research and Technology, 4, 33-43 (2015).

DOI: $10.1016 /$ j.jmrt.2014.10.016

[47] Karger-Kocsis J., Mahmood H., Pegoretti A.: Recent advances in fiber/matrix interphase engineering for polymer composites. Progress in Materials Science, 73, 1-43 (2015).

DOI: $10.1016 /$ j.pmatsci.2015.02.003

[48] Jones A. R., Cintora A., White S. R., Sottos N. R.: Autonomic healing of carbon fiber/epoxy interfaces. ACS Applied Materials Interfaces, 6, 6033-6039 (2014). DOI: $10.1021 / \mathrm{am} 500536 \mathrm{t}$

[49] Jones A. R., Blaiszik B. J., White S. R., Sottos N. R.: Full recovery of fiber/matrix interfacial bond strength using a microencapsulated solvent-based healing system. Composites Science and Technology, 79, 1-7 (2013). DOI: $10.1016 /$ j.compscitech.2013.02.007

[50] Ahangari M. G., Fereidoon A.: Micromechanical properties and morphologies of self-healing epoxy nanocomposites with microencapsulated healing agent. Materials Chemistry and Physics, 151, 112-118 (2015). DOI: $10.1016 /$ j.matchemphys.2014.11.044

[51] Stankiewicz A., Szczygieł I., Szczygieł B.: Self-healing coatings in anti-corrosion applications. Journal of Materials Science, 48, 8041-8051 (2013). DOI: $10.1007 / \mathrm{s} 10853-013-7616-\mathrm{y}$

[52] Jadhav R. S., Hundiwale D. G., Mahulikar P. P.: Synthesis and characterization of phenol-formaldehyde microcapsules containing linseed oil and its use in epoxy for self-healing and anticorrosive coating. Journal of Applied Polymer Science, 119, 2911-2916 (2011). DOI: 10.1002/app.33010

[53] Samadzadeh M., Boura S. H., Peikari M., Ashrafi A., Kasiriha M.: Tung oil: An autonomous repairing agent for self-healing epoxy coatings. Progress in Organic Coatings, 70, 383-387 (2011). DOI: 10.1016/j.porgcoat.2010.08.017

[54] Zhang H., Wang J., Liu X., Wang Z., Wang S.: High performance self-healing epoxy/polyamide protective coating containing epoxy microcapsules and polyaniline nanofibers for mild carbon steel. Industrial and Engineering Chemistry Research, 52, 10172-10180 (2013). DOI: $10.1021 /$ ie400666a
[55] Sun D., An J., Wu G., Yang J.: Double-layered reactive microcapsules with excellent thermal and non-polar solvent resistance for self-healing coatings. Journal of Materials Chemistry A, 3, 4435-4444 (2015).

DOI: 10.1039/C4TA05339G

[56] Sinha-Ray S., Pelot D. D., Zhou Z. P., Rahman A., Wu X-F., Yarin A. L.: Encapsulation of self-healing materials by coelectrospinning, emulsion electrospinning, solution blowing and intercalation. Journal of Materials Chemistry, 22, 9138-9146 (2012).

DOI: $10.1039 / \mathrm{c} 2 \mathrm{jm} 15696 \mathrm{~b}$

[57] Wu X-F., Rahman A., Zhou Z., Pelot D. D., Sinha-Ray S., Chen B., Yarin A. L.: Electrospinning core-shell nanofibers for interfacial toughening and self-healing of carbon-fiber/epoxy composites. Journal of Applied Polymer Science, 129, 1383-1393 (2013).

DOI: $10.1002 / a p p .38838$

[58] Mitchell T. J., Keller M. W.: Coaxial electrospun encapsulation of epoxy for use in self-healing materials. Polymer International, 62, 860-866 (2013).

DOI: $10.1002 /$ pi.4397

[59] Yarin A. L., Zussman E., Wendorff J. H., Greiner A.: Material encapsulation and transport in core-shell micro/ nanofibers, polymer and carbon nanotubes and micro/ nanochannels. Journal of Materials Chemistry, 17, 2585-2599 (2007).

DOI: $10.1039 / \mathrm{b} 618508 \mathrm{~h}$

[60] Yarin A. L.: Coaxial electrospinning and emulsion electrospinning of core-shell fibers. Polymers for Advanced Technologies, 22, 310-317 (2011).

DOI: $10.1002 /$ pat.1781

[61] Vahedi V., Pasbakhsh P., Piao C. S., Seng C. E.: A facile method for preparation of self-healing epoxy composites: using electrospun nanofibers as microchannels. Journal of Materials Chemistry A, 3, 16005-16012 (2015).

DOI: 10.1039/C5TA02294K

[62] Pang J. W. C., Bond I. P.: A hollow fibre reinforced polymer composite encompassing self-healing and enhanced damage visibility. Composites Science and Technology, 65, 1791-1799 (2005). DOI: 10.1016/j.compscitech.2005.03.008

[63] Trask R. S., Bond I. P.: Biomimetic self-healing of advanced composite structures using hollow glass fibres. Smart Materials and Structures, 15, 704-710 (2006). DOI: 10.1088/0964-1726/15/3/005

[64] Trask R. S., Williams G. J., Bond I. P.: Bioinspired selfhealing of advanced composite structures using hollow glass fibres. Journal of the Royal Society Interface, 4, 363-371 (2007). DOI: $10.1098 /$ rsif.2006.0194

[65] Mehta N. K.: Self-healing fiber-reinforced epoxy composites: Solvent-epoxy filled hollow glass fibers. International Journal of Composite Materials, 3, 145-155 (2013).

DOI: $\underline{10.5923 / \mathrm{j} . c m a t e r i a l s .20130306 .02}$ 
[66] Williams G., Trask R., Bond I.: A self-healing carbon fibre reinforced polymer for aerospace applications. Composites Part A: Applied Science and Manufacturing, 38, 1525-1532 (2007).

DOI: 10.1016/j.compositesa.2007.01.013

[67] Kling S., Czigány T.: Damage detection and self-repair in hollow glass fiber fabric-reinforced epoxy composites via fiber filling. Composites Science and Technology, 99, 82-88 (2014).

DOI: $10.1016 /$ j.compscitech.2014.05.020

[68] Zhang H., Yang J.: Etched glass bubbles as robust micro-containers for self-healing materials. Journal of Materials Chemistry A, 1, 12715-12720 (2013). DOI: $10.1039 /$ C3TA13227G

[69] Zhang H., Wang P., Yang J.: Self-healing epoxy via epoxy-amine chemistry in dual hollow glass bubbles. Composites Science and Technology, 94, 23-29 (2014). DOI: 10.1016/j.compscitech.2014.01.009

[70] Kirk J. G., Naik S., Moosbrugger J. C., Morrison D. J., Volkov D., Sokolov I.: Self-healing epoxy composites based on the use of nanoporous silica capsules. International Journal of Fracture, 159, 101-102 (2009). DOI: $10.1007 / \mathrm{s} 10704-009-9375-\mathrm{y}$

[71] Liu M., Guo B., Du M., Cai X., Jia D.: Properties of halloysite nanotube-epoxy resin hybrids and the interfacial reactions in the systems. Nanotechnology, 18, 455703/1-455703/9 (2007). DOI: $10.1088 / 0957-4484 / 18 / 45 / 455703$

[72] Ye Y., Chen H., Wu J., Ye L.: High impact strength epoxy nanocomposites with natural nanotubes. Polymer, 48, 6426-6433 (2007).

DOI: 10.1016/j.polymer.2007.08.035

[73] Deng S., Zhang J., Ye L., Wu J.: Toughening epoxies with halloysite nanotubes. Polymer, 49, 5119-5127 (2008).

DOI: 10.1016/j.polymer.2008.09.027

[74] Abdullayev E., Lvov Y.: Halloysite clay nanotubes for controlled release of protective agents. Journal of Nanoscience and Nanotechnology, 11, 10007-10026 (2011). DOI: 10.1166/jnn.2011.5724

[75] Lvov Y., Abdullayev E.: Functional polymer-clay nanotube composites with sustained release of chemical agents. Progress in Polymer Science, 38, 1690-1719 (2013).

DOI: 10.1016/j.progpolymsci.2013.05.009

[76] Melo J. D. D., Barbosa A. P. C., Costa M. C. B., de Melo G. N.: Encapsulation of solvent into halloysite nanotubes to promote self-healing ability in polymers. Advanced Composite Materials, 23, 507-519 (2014). DOI: 10.1080/09243046.2014.915116

[77] Abdullayev E., Lvov Y.: Clay nanotubes for corrosion inhibitor encapsulation: Release control with end stoppers. Journal of Materials Chemistry, 20, 6681-6687 (2010).

DOI: $10.1039 / \mathrm{c} 0 \mathrm{jm} 00810 \mathrm{a}$
[78] Abdullayev E., Abbasov V., Tursunbayeva A., Portnov V., Ibrahimov H., Mukhtarova G., Lvov Y.: Self-healing coatings based on halloysite clay polymer composites for protection of copper alloys. ACS Applied Materials and Interfaces, 5, 4464-4471 (2013). DOI: $10.1021 / \mathrm{am} 400936 \mathrm{~m}$

[79] Skorb E. V., Fix D., Andreeva D. V., Möhwald H., Shchukin D. G.: Surface-modified mesoporous $\mathrm{SiO}_{2}$ containers for corrosion protection. Advanced Functional Materials, 19, 2373-2379 (2009).

DOI: $10.1002 / \mathrm{adfm} .200801804$

[80] Maia F., Tedim J., Lisenkov A. D., Salak A. N., Zheludkevich M. L., Ferreira M. G. S.: Silica nanocontainers for active corrosion protection. Nanoscale, 4, 12871298 (2012).

DOI: $10.1039 / \mathrm{c} 2 \mathrm{nr} 11536 \mathrm{k}$

[81] Qiao Y., Li W., Wang G., Zhang X., Cao N.: Application of ordered mesoporous silica nanocontainers in an anticorrosive epoxy coating on a magnesium alloy surface. RSC Advances, 5, 47778-47787 (2015).

DOI: 10.1039/C5RA05266A

[82] Shi X., Nguyen T. A., Suo Z., Liu Y., Avci R.: Effect of nanoparticles on the anticorrosion and mechanical properties of epoxy coating. Surface and Coatings Technology, 204, 237-245 (2009).

DOI: $10.1016 /$ j.surfcoat.2009.06.048

[83] Moazeni N., Mohamad Z., Faisal N. L. I., Tehrani M. A., Dehbari N.: Anticorrosion epoxy coating enriched with hybrid nanozinc dust and halloysite nanotubes. Journal of Applied Polymer Science, 130, 955-960 (2013).

DOI: 10.1002/app.39239

[84] Wang Z., Liang Z., Wang B., Zhang C., Kramer L.: Processing and property investigation of single-walled carbon nanotube (SWNT) buckypaper/epoxy resin matrix nanocomposites. Composites Part A: Applied Science and Manufacturing, 35, 1225-1232 (2004).

DOI: 10.1016/j.compositesa.2003.09.029

[85] Suzuki N., Kiba S., Yamauchi Y.: Fabrication of mesoporous silica/polymer composites through solvent evaporation process and investigation of their excellent low thermal expansion property. Physical Chemistry Chemical Physics, 13, 4957-4962 (2011).

DOI: $10.1039 / \mathrm{c} 0 \mathrm{cp} 02071 \mathrm{k}$

[86] Lanzara G., Yoon Y., Liu H., Peng S., Lee W-I.: Carbon nanotube reservoirs for self-healing materials. Nanotechnology, 20, 335704/1-335704/7 (2009). DOI: $10.1088 / 0957-4484 / 20 / 33 / 335704$

[87] Ye X. J., Zhang J-L., Zhu Y., Rong M. Z., Zhang M. Q., Song Y. X., Zhang H-X.: Ultrafast self-healing of polymer toward strength restoration. ACS Applied Materials and Interfaces, 6, 3661-3670 (2014). DOI: $10.1021 / \mathrm{am} 405989 \mathrm{~b}$

[88] Zhang H., Yang J.: Development of self-healing polymers via amine-epoxy chemistry: II. Systematic evaluation of self-healing performance. Smart Materials and Structures, 23, 065004/1-065004/9 (2014). DOI: $10.1088 / 0964-1726 / 23 / 6 / 065004$ 
[89] Rule J. D., Sottos N. R., White S. R.: Effect of microcapsule size on the performance of self-healing polymers. Polymer, 48, 3520-3529 (2007).

DOI: $10.1016 /$ j.polymer.2007.04.008

[90] Brown E. N., White S. R., Scottos N. R.: Retardation and repair of fatigue cracks in a microcapsule toughened epoxy composite - Part II: In situ self-healing. Composites Science and Technology, 65, 2474-2480 (2005).

DOI: 10.1016/j.compscitech.2005.04.053

[91] Tripathi M., Kumar D., Rajagopal C., Roy P. K.: Curing kinetics of self-healing epoxy thermosets. Journal of Thermal Analysis and Calorimetry, 119, 547-555 (2014).

DOI: $10.1007 / \mathrm{s} 10973-014-4128-1$
[92] Aïssa B., Therriault D., Haddad E., Jamroz W.: Self-healing materials systems: Overview of major approaches and recent developed technologies. Advances in Materials Science and Engineering, 2012, 854203/1$854203 / 17$ (2012).

DOI: $10.1155 / 2012 / 854203$

[93] Tems R., Al Zahrani A. M.: Cost of corrosion in oil production and refining. Saudi Aramco Journal of Technology, 2-14 (2006).

[94] Lvov Y. M., Shchukin D. G., Möhwald H., Price R. R.: Halloysite clay nanotubes for controlled release of protective agents. ACS Nano, 2, 814-820 (2008).

DOI: $10.1021 / \mathrm{nn} 800259 \mathrm{q}$

[95] Kamble R., Ghag M., Gaikawad S., Panda B. K.: Halloysite nanotubes and applications: A review. Journal of Advanced Scientific Research, 3, 25-26 (2012). 